\title{
TU/e ENHOUEN

\section{Reduced kernel IE's for MEN based analysis of multilayered FSS structures}

\section{Citation for published version (APA):}

Monni, S., Neto, A., Tijhuis, A. G., \& Gerini, G. (2005). Reduced kernel IE's for MEN based analysis of multilayered FSS structures. In Proceedings of the 2005 IEEE Antennas and Propagation Society International Symposium, 3-8 July 2005, Washington, DC (pp. 388-391). Institute of Electrical and Electronics Engineers. https://doi.org/10.1109/APS.2005.1552673

DOI:

10.1109/APS.2005.1552673

Document status and date:

Published: 01/01/2005

\section{Document Version:}

Publisher's PDF, also known as Version of Record (includes final page, issue and volume numbers)

\section{Please check the document version of this publication:}

- A submitted manuscript is the version of the article upon submission and before peer-review. There can be important differences between the submitted version and the official published version of record. People interested in the research are advised to contact the author for the final version of the publication, or visit the $\mathrm{DOI}$ to the publisher's website.

- The final author version and the galley proof are versions of the publication after peer review.

- The final published version features the final layout of the paper including the volume, issue and page numbers.

Link to publication

\section{General rights}

Copyright and moral rights for the publications made accessible in the public portal are retained by the authors and/or other copyright owners and it is a condition of accessing publications that users recognise and abide by the legal requirements associated with these rights.

- Users may download and print one copy of any publication from the public portal for the purpose of private study or research.

- You may not further distribute the material or use it for any profit-making activity or commercial gain

- You may freely distribute the URL identifying the publication in the public portal.

If the publication is distributed under the terms of Article 25fa of the Dutch Copyright Act, indicated by the "Taverne" license above, please follow below link for the End User Agreement:

www.tue.nl/taverne

Take down policy

If you believe that this document breaches copyright please contact us at:

openaccess@tue.nl

providing details and we will investigate your claim. 


\title{
Reduced Kernel IE's for MEN Based Analysis of Multilayered FSS Structures
}

\author{
S. Monni, A. Neto ${ }^{1}$, A. G. Tijhuis ${ }^{2}$, and G. Gerini ${ }^{1}$ \\ ${ }^{1}$ TNO Defence, Safety and Security, \\ Oude Waalsdorperweg 63, 2597 AK The Hague, The Netherlands \\ ${ }^{2}$ Eindhoven University of Technology, Faculty of Electrical \\ Engineering, $5600 \mathrm{MB}$ Eindhoven, The Netherlands
}

\section{Introduction}

Despite the fact that the general behavior of periodic structures has been investigated for many decades, the analysis and design of multilayered FSS's is still a very actual and complicated problem. This is especially true for stringent requirements, which rise for example when the FSS has to be integrated with a planar phased array. A MEN based approach has been developed to solve this specific kind of problems and successfully applied to a realistic design case [1]. The key innovative notion introduced by the MEN method is the formalization of the scattering problem through a set of Integral Equations (IE's) with reduced kernel and corresponding reduced Green's Function (GF). Originally, the pertinent Method of Moments (MoM) based IE's have been solved by expanding the unknowns in terms of sub-domain functions. However, when the frequency filtering performances required from the FSS include steep roll offs and wide scan angles, the number of accessible (interacting) modes to be included in the analysis grows and it turns out that, for expansions based on sub-domain functions, the MoM matrix tends to be ill conditioned. This specific behavior will be the subject of this contribution.

\section{D TM Problem: IE formulation with sub- and entire-domain basis functions}

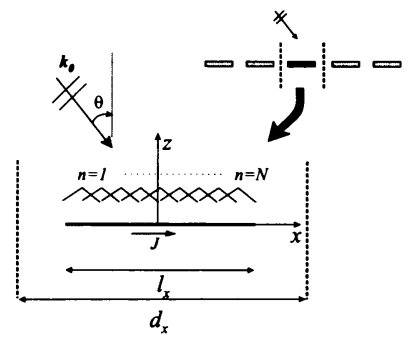

Figure 1: Geometry of the investigated 2D problem: infinite periodic array under TM plane wave incidence.

Fig. 1 shows the investigated geometry. It consists of an infinite periodic array of metallic strips in free space, with period $d_{x}$ and strip length $\ell_{x}$. The incident wave is assumed to be TM polarized with respect to the $z$-axis. As explained in [1], a dipole FSS can be characterized in terms of a shunt discontinuity, represented 
by a multimode admittance network, with respect to the (multimode) transmission line equivalent to the Floquet Wave (FW) representation of the field. This admittance network is obtained from the solution of a set of IE's whose forcing terms are the transverse modal electric fields associated to the accessible FW's: $e_{i}=\frac{1}{\sqrt{d_{x}}} e^{-j k_{x_{0}}-\frac{2 \pi i}{d_{x}} x}$. In this expression, $k_{x_{0}}=k_{0} \sin \theta$ is the phase shift of the excitation law in the $x$ direction, $i=-N_{a} . . N_{a}$ is the index of the considered accessible mode, with $N=2 N_{a}+1$ the total number of accessible modes, and $k_{x_{i}}=k_{x_{0}}-\frac{2 \pi i}{d_{x}}$ is the modal transverse wavenumber. The complete set of IE's in this simple case can then be expressed as:

$$
\int_{-l_{x} / 2}^{l_{x} / 2} g_{n a}^{e}\left(x-x^{\prime}\right) \cdot j_{i}\left(x^{\prime}\right) d x^{\prime}=-\frac{1}{\sqrt{d_{x}}} e^{-j k_{x_{0}}-\frac{2 \pi i}{d_{x}} x}
$$

where $j_{i}(x)$ are the unknown equivalent currents induced on the patch by an impressed electric field equal to the $i$-th FW (electric field) mode. A key aspect characterizing these IE's is the fact that their kernels are reduced to the non-accessible portion of the GF's, $g_{n a}^{e}$. In the specific free space two dimensional case considered in this contribution, $g_{n a}^{e}$ results to be:

$$
g^{e}\left(x, x^{\prime}\right)=\sum_{m=-\infty}^{\infty} g_{m}^{e}\left(x, x^{\prime}\right)=C_{g} \sum_{m=-\infty}^{\infty} \sqrt{k_{0}^{2}-k_{x_{m}}^{2}} e^{-j k_{x_{m}}\left(x-x^{\prime}\right)}
$$

with $C_{g}=-\frac{1}{4 \pi \omega \varepsilon}$. The non-accessible portion of the GF due to $N$ accessible modes is $[1]$

$$
\frac{1}{C_{g}} g_{n a}^{e}\left(x, x^{\prime}\right)=\sum_{m=-\infty}^{\infty} g_{m}^{e}\left(x, x^{\prime}\right)-\sum_{m=-N_{a}}^{N_{a}} g_{m}^{e}\left(x, x^{\prime}\right)
$$

Fig. 2 presents parametric curves (for different $N_{a}$ indices) of the amplitude of the non-accessible fields, generated by a current distributed according to a pws rule. The calculations have been performed without resorting to the previous approximation for the GF. In particular, we have used one pws function, centered in the origin of the reference system in Fig. 1, with length $\ell_{\mathrm{PWS}}=0.01 \lambda_{0}$. The period of the structure is $d_{x}=0.6 \lambda_{0}$ and the field is observed on the entire periodic cell. The array is supposed to be radiating broadside, $k_{x_{0}}=k_{0} \sin \theta=0$ and, therefore, the entire non-accessible field is purely imaginary. Both a dominant singularity, (in $x=0$ ), and some periodic oscillations can be recognized. Moreover, for any value of $N_{a}$ larger than one, the amplitude of the radiated field is not always decreasing as the distance between source and observer (or image and observer) increases. For large $N_{a}$ the oscillations are very relevant.

Piece wise sinusoidal functions are widely used for studying, via MoM, dipole antennas. However, these functions have a number of disadvantages, especially when introduced in a MEN procedure. In this case, since the forcing terms (FW's) are 
periodic functions of $x$, the solutions tend also to be highly oscillatory in nature. Additionally, for high values of $N_{a}$, the non-accessible GF is essentially frequency independent, and so are the entries of the corresponding MoM. Furthermore, the non diagonal terms of the matrix tend to have a non decreasing and oscillating nature. Fig. 3a shows a parametric study of the condition numbers of the MoM matrices generated when solving, via pws-based MoM, the scattering problem of an array of metallic strips under TM incidence. The condition numbers are plotted as a function of the accessible mode index $N_{a}$; the strips length ranges from small with respect to the wavelength to a dimension of the order of magnitude of the array period $\left(d_{x}=0.6 \lambda_{0}\right)$. In all cases, 101 pws functions were considered. As expected, the condition number grows with $N_{a}$. Moreover, one can notice that the growth is much faster when the dimensions of the strip are comparable with the period. The intuitive reason is that the natural modes of the structure tend to resonate with the Floquet modes. When this happens, the problem becomes wildly ill conditioned. For dimensions of the strip close to the period the problem cannot be treated already for $N_{a}=1$, while for shorter strips the coherence between Floquet modes and natural modes of the structure can only occur for large $N_{a}$. This type of ill conditioning is essentially frequency independent, unlike what is typically found in most MoM based formulations.

A general-purpose procedure, to reduce the required numerical effort, consists in the adoption of entire-domain basis functions. Since, for the case of reduced kernels, eigenfunctions tend to be similar to combinations of the extracted FW's, it might be convenient to use those same FW's as basis functions. This idea is supported by the observation that the non-accessible GF is dominated, especially for large $N_{a}$ values, by the Floquet wavenumbers. In [2] Truncated Floquet Waves (tfw) were proposed as entire domain basis functions for the analysis of large finite slot arrays (2D geometries). The functions introduced here are defined only on the domain of the radiating element inside the periodic cell, rather than in the all finite-array domain. In this case, it is convenient to account for the end point appropriate boundary conditions and, since the scale of the problem (periodic cell) is typically sub-wavelength, the dominant edge conditions are the quasi-static ones. In Fig. 3b, a comparison between the currents calculated via the MoM, when using pws basis functions and tfw's is presented. The strip investigated in this example is $0.2 \lambda_{0}$ long, with a period $d_{x}=0.6 \lambda_{0}$ and $N_{a}=2$. Resorting to only three tfw's achieves the same accuracy as using 101 pws functions.

\section{Conclusions}

The use of sub-domain basis functions for solving via MoM the IE's that arise from a MEN formulation leads to ill conditioned problems. This happens especially for large number of accessible modes, $N_{a}$. In such cases, basis functions with oscillations dominated by the period of the structures and with pertinent boundary conditions to verify the local geometrical configurations turned out to be more adequate. During the oral presentation a number of test cases, demonstrating the efficacy of TFW's as basis functions, will be proposed, as well as an asymptotic expansion of the GF for large values of $N_{a}$ and consequent discussion on the nature of the eigenvalues of 


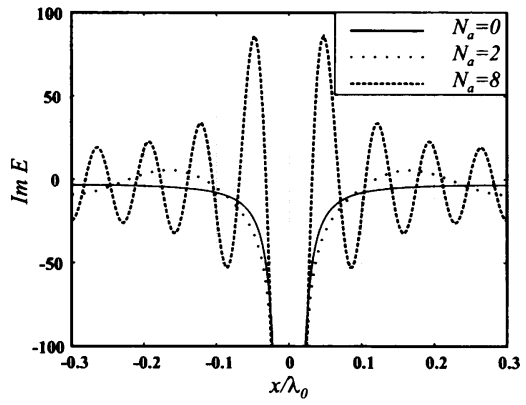

Figure 2: Non-accessible Green's function as a function of the $x$ coordinate.

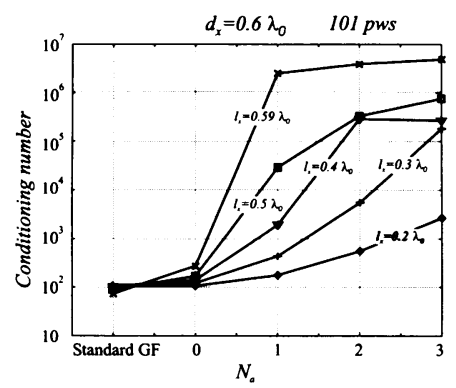

(a)

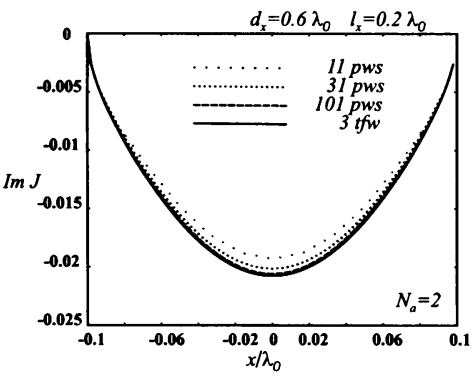

(b)

Figure 3: Properties of sub- and entire- domain basis functions for reduced kernel IE's. (a)Condition number of the MoM matrix. (b)Electric currents in the TM case.

the reduced Kernel integral equations.

\section{References}

[1] S. Monni, G. Gerini , A. Neto, A. G. Tijhuis, "Multimode Equivalent Network Method for the Design and Analysis of Frequency Selective Surfaces Integrated with Waveguide Arrays," submitted for publication to IEEE Trans. Antennas Propagat..

[2] A. Neto, S. Maci, G. Vecchi, and M. Sabbadini, "A truncated floquet wave diffraction method for the full-wave analysis of large phased arrays. Part I: basic principle and 2-d case." IEEE Trans. Antennas and Propagation, AP-48(4):594$600,2000$. 